\title{
The Change of the Trunk Muscles Activation in the Adolescent Carrying a Backpack with Belts
}

\author{
Yong Soo Kong', Jang Soon Yoon ${ }^{2}$ \\ ${ }^{1}$ Department of Physical Therapy, Fatima Clinic, Donghae, 240-180 \\ ${ }^{2}$ Department of Physical Therapy, Chuncheon Sacred Heart, Hallym University, Chuncheon, 200-702
}

\begin{abstract}
Objective: The purpose of this study is to compare the EMG activities of the trunk muscles when carrying a backpack with belts and without belts. Background: This research aimed to explore the influence of carrying a backpack with belts on the trunk muscles activity and to suggest a desirable method of wearing backpacks. Method: Seventy five adolescents participated in this study. The EMG activities of upper trapezious, cervical erector spinae and rectus abdominis were collected. One way ANOVA was used to analyze the collected data. LSD was used for post-hoc test. Results: The EMG data from treadmill walking showed significant differences between carrying a backpack with belts and without belts for the cervical erector spinae and upper trapezious $(p<.05)$ in all group(A Group: no belt, B Group: lumbar belt, C Group: lumbar-chest belt). In descending walking, significant difference were found for the cervical erector spinae and rectus abdominis in all group. In ascending walking, there were no significant differences in all group. LSD showed that the muscle activity of the trunk muscles decreased significantly when the lumbar belt and lumbar-chest belt were worn. Conclusion: The trunk muscles activities were decreased when the subjects were wearing a backpack with belts, comparing with wearing a backpack without belts. Application: These results can be used to provide useful information on how wearing a backpack in adolescent.
\end{abstract}

Keywords: Backpack, EMG, Muscle activity

\section{Introduction}

학령기 아동들의 가장 중요한 작업 중 하나는 학교 수업 에 참여하고, 교과서 및 수업 준비물을 넣은 책가방을 메고 다니는 것이다(Pascoe et al., 1997). 학생들의 책가방은 책과 노트로 채워져 있으며, 하루 종일 과부하를 동반한다. 이것이 장기적으로 신체에 미치는 영향은 알지 못하지만, 무 거운 책가방을 나르는 반복적인 스트레스는 학생들에서 관 찰되는 근골격계 증상의 높은 유병률에 기여한다(Whittfield et al., 2001).
최근 연구에 의하면 무거운 책가방이 성장기 관절과 인대 에 압력을 주게 되며 이것이 잠재적으로 허리 통증의 원인이 될 수 있으며, 보건 건강 분야의 많은 예산이 근골격계와 관 련된 분야로 지출되고 있다(Forjuoh et al., 2003). 학생들의 무거운 책가방은 근육 통증뿐 아니라 허리긴장, 걸음걸이의 비대칭 보행, 나쁜 자세 및 요통을 포함한 근골격계의 건강 에 이상을 초래한다. 그리고 학생들에 있어 인대 및 성장 관 절에 압박을 줄 수 있으며, 허리 손상을 일으키는 원인이 된 다(Pascoe et al., 1997). 미국에서는 무거운 가방의 무게 는 아동의 체중에 $17.7 \%$ 나 된다고 하였고(Pascoe et al., 1997), 이탈리아(Negrini \& Carabalona, 2002)에서는 20\%,

Corresponding Author: Yong Soo Kong. Department of Physical Therapy, Fatima Clinic, Donghae, 240-180.

Mobile: +82-17-350-2108, E-mail: twinkong@hanmail.net

Copyright@2012 by Ergonomics Society of Korea(pISSN:1229-1684 eISSN:2093-8462). All right reserved.

(c) This is an open-access article distributed under the terms of the Creative Commons Attribution Non-Commercial License(http://creativecommons.org/licenses/by-nc/3.0/), which permits unrestricted non-commercial use, distribution, and reproduction in any medium, provided the original work is properly cited. http://www.esk.or.kr 
그리고 홍콩(Hong Kong Society for Child Health and Development, 1988)에서도 20\%나 된다고 보고하였다. 또 한 근 피로와 통증, 허리 통증, 감각이상 어깨 통증과 심지 어 척추 변형과 같은 척추 증상이 가방을 메는 습관과 깊은 연관이 있다는 것을 보였다(Grimmer et al., 1999; Negrini \& Carabalona, 2002; Pascoe et al., 1997).

이와 같이 가방을 메는 방법에 따라 어떠한 영향이 있는지 에너지 소비 (Hong et al., 2000), 심폐반응 (Li et al., 2003), 체간 자세(Chansirinukor et al., 2001) 그리고 보행운동학 (Hong \& Li, 2005) 등 많은 생리학적인 연구 결과가 나왔 다. 가방은 머리의 위치와 체간을 앞으로 기울어지게 함으로 써 한쪽 어깨로 가방을 착용할 때 어깨가 상승하고, 가방 무 게로부터 어깨를 떨어지게 만들어, 척추의 커브가 한쪽으로 휘게 되는 것을 관찰하였다. 그리고 2 개의 스트랩이 사용된 가방은 이러한 스트레스가 감소되었으며, 가방의 무게가 주 어질 때 보폭이 감소하였고, 보행을 증가시키는 보행의 변화 또한 가져 왔다(Pascoe et al., 1997). 이에 대한 적응기전으 로 신체는 평형을 유지하고 에너지 소모를 최소화하기 위해 신체 분절을 비정상적인 자세로 재정렬하여 체중심선을 기 저면 중앙과 전방으로 이동시키게 된다(Oh \& Choi, 2007; Jo, 2001). 이와 같이 무거운 가방과 올바르지 못한 휴대 방식은 보행 중에 비정상적인 자세를 유발하고 체간 안정성 (Lee et al., 2007) 과 근골격계에 영향을 주어 통증과 척추 장애를 유발할 뿐만 아니라 신체에 전반적인 불균형을 초래 할 수 있다(Gong et al., 2009). 이러한 문제점을 해결하고 올바른 휴대 방법을 제시하기 위해 가방의 무게(Forjuoh et al., 2003) 와 길이 (Oh \& Choi, 2007)그리고 보행 (Pascoe et al., 1997)에 미치는 영향에 대하여 많은 연구가 선행되었 지만, 가방의 착용 방법(Motmans et al., 2006)에 대한 연 구는 미흡한 실정이다. 따라서 본 연구에서는 가방을 휴대하 는 방법에 따라 허리 및 허리-흉부벨트를 적용함으로써 가 방을 착용하였을 때 체간 근육의 근활성도를 연구함으로 청 소년에 있어서 올바른 가방 휴대 방법에 대한 새로운 기초 자료를 제시하고자 본 연구를 실시하였다.

\section{Method}

\subsection{Subject}

본 연구의 대상자는 실험의 목적과 방법에 대한 설명을 들 은 후 본 실험에 참여할 것을 동의한 동해시 소재 초, 중등 학교 5 개교의 학생들을 대상으로 실시하였다. 대상자의 선 정 기준은 근골격계 통증을 호소하지 않는 건강한 학생, 정 형외과적 또는 신경외과적 질환이 없는 자, 부모님에게 연구
의 목적과 과정을 설명하였으며, 이에 동의한 학생으로 하 였다.

\subsection{Equipment}

본 연구에서 사용된 배낭형 가방은 일반 시중에서 많이 사 용되는 틀(Frame)이 없는 가방(No belt; A-Group)이며, 개인의 편의를 위하여 어깨끈은 편하도록 조절을 하였다. 허 리벨트(Lumbar Belt; B-Group)를 착용한 가방은 일반적인 배낭형 가방으로 허리 부분에 벨트를 하여 고정을 하였다. 허리벨트는 실험자가 편하도록 조절을 하였다. 그리고 허리 -흥부벨트(Lumbar-chest Belt; C-Group)를 착용한 가방 은 일반적인 배낭형 가방으로 허리, 흉부에 벨트를 하여 고 정을 하였다. 허리-흉부벨트는 실험자가 편하도록 조절을 하였다(Figure 1).

체간 근육의 활성도를 측정하기 위해 표면 근전도(MP150, Biopac System, USA)를 이용하였으며, 전극은 $\mathrm{Ag}-\mathrm{Ag} / \mathrm{Cl}$ (Biopac, diameter $2 \mathrm{~cm}$ )을 사용하여 측정하였다. 근전도 의 신호는 $1,000 \mathrm{~Hz}$ 의 sampling rate의 신호획득률로 수집 한 후 Full-wave rectification로 처리하였다. 자료정리는 Acqknowledge 3.8.1 (Biopac System, USA) 소프트웨어를 이용하여 30 500Hz에서 구간 필터링 (Band pass filtering) 하고 잡음제거를 위하여 $60 \mathrm{~Hz}$ 로 notch 필터링하여 신호를 처리하였다.

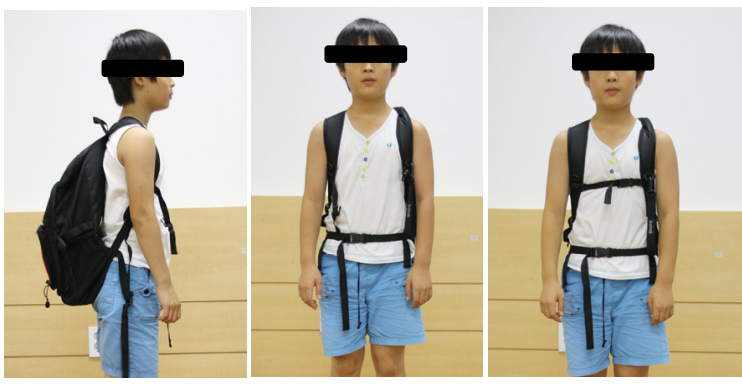

Figure 1. Backpack and type of backpack's belt

체간 근육의 근활성도를 보기 위하여 상부승모근(upper trapezius), 경부척추기립근(cervical erector spine), 복직 근(rectus abdominalis)을 선택하였다. 전극의 위치는 각 실험자의 우세손 쪽에 위치하도록 그리고 체간 양쪽면의 근 육의 패턴이 비슷하다는 가정하에 한쪽면에 적극을 부착을 하였으며 기존의 연구 문헌을 참조하여 각 근육의 전극부착 부위를 유성펜으로 작게 표시하였다(Cram et al., 1998) (Figure 2).

실험 시 체간 근육의 근전도 신호를 정규화하기 위하여 체 


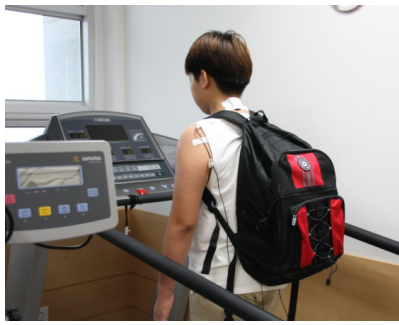

Figure 2. Subject walking procedure with EMG

간상부의 경부척추기립근은 서있는 자세에서 목을 뒤로 신 전시키는 자세를 하였고, 상부승모근은 서있는 자세에서 어 깨를 들어올리는 동작을 하였다. 체간의 중심이 되는 복직근 은 누워있는 자세에서 손을 뒤로 하여 허리를 굴곡하는 동 작을 하여 각 근육을 5 초 동안 최대 등척성 수축(Maximal Voluntary Isometric Contraction; MVIC) 시 발생되는 근 활성도를 측정하였다. 10 분 간의 근전도 신호 수집에서 측정 된 자료 값은 평균제곱근(root mean square: RMS) 처리한 후 처음과 끝의 10 초 씩을 제외한 뒷 부분의 9 분 20 초부터 9 분 50 초까지 30 초 구간의 데이터를 샘플링하여 평균 근전 도 신호량을 $100 \% \mathrm{MVIC}$ 로 사용하였다.

\subsection{Procedure}

대상자에게는 자기기입식 (self-reported questionnaire) 설문조사를 하였으며, 설문조사는 일반적 특성, 가방의 무게, 벨트의 사용유무, 사물함 이용, 가방 휴대 방법 그리고 가방 의 만족도로 구성을 하였다. 가방의 무게는 체중의 $15 \%$ 로 하였고, 사전검사에서 개인의 몸무게를 측정한 후 체중의 $15 \%$ 부하를 배낭형 가방의 무게로 정하였다(Limon et al., 2004). 이 무게를 만들기 위하여 체중계(nBody, NB-HM, Korea)를 이용하여 학생들이 사용하는 노트, 책을 사용하여 가방의 무게를 조절하였다.

실험자들은 트래드밀 및 계단에서 걷는 것이 익숙해 지도 록 5 분의 시간을 주어 걷게 하였으며, 실험자는 표면 근전도 측정을 위하여 민소매 셔츠, 양말과 스포츠 운동화를 착용하 였다. 근육의 피로도를 줄이기 위하여 실험 사이에 10 분 간 의 휴식을 실시하였으며, 근전도 전극을 상부승모근, 복직 근, 경부척추기립근에 부착하여 근활성도를 측정하였다. 측 정 전 서있는 자세에서 각 근육의 근전도 신호가 정상적인 신호를 나타나는지를 확인한 후 본 실험을 실시하였다. 그리 고 전극의 움직임을 방지하기 위하여 반창고로 전극을 고정 을 하였다. 실험자의 시선은 전방을 주시하면서 트래드밀 위 에서 $1.1 \mathrm{~m} / \mathrm{s}$ 속도로 10 분 간 보행을 하였다(Wong \& Hong, 1997). 그리고 계단 보행은 코너 계단(corner stairs)을 이
용하여 자연스럽게 보행을 하도록 하였다.

\subsection{Data analysis}

수집된 자료는 SPSS 18 PASW Statistics를 이용하여 통계처리 하였으며, 일반적 특성을 알아보기 위하여 빈도분 석, 기술통계를 사용하였다. 각 그룹별 벨트착용 방법에 따 른 경부척추기립근, 상부승모근, 복직근의 근활성도를 보기 위하여 일원배치 분산분석(one-way ANOVA)을 실시하였 다. 사후검정 방법으로 최소유의차 사후검정 (LSD)을 실시 하였으며, 유의 수준은 $p<.05$ 로 하였다.

\section{Results}

\subsection{General characteristic}

본 연구에 참석한 대상자는 총 75 명 이였고, 남학생 43 명 $(57.3 \%)$, 여학생 32 명 $(42.7 \%)$ 이였다. 이중 중학생은 28 명 $(37.3 \%)$, 초등학생 47 명 $(62.7 \%)$ 이였다. 이들의 평균 나이 는 13.24 세, 평균 키는 $153.89 \mathrm{~cm}$, 평균 몸무게는 $48.3 \mathrm{~kg}$ 이였다. 가방의 벨트를 사용하는 학생은 A그룹 3명 (12\%), $\mathrm{B}$ 그룹 5명(20\%), C그룹 3명(12\%), 총 11명(14.70\%)이 였고, 벨트를 사용하지 않는 학생은 64명 (85.30\%)이였다. 사물함을 사용하는 학생은 9명 $(12 \%)$, 사물함을 사용하지 않는 학생은 66 명 $(88 \%)$ 이고, 가방의 무게는 가볍다고 한 학생은 7명 (9.3\%), 보통이다 30명 $(40 \%)$, 무겁다 29명 $(38.7 \%)$ 이였다(Table 1).

\subsection{Muscle activity in treadmill walking}

가방을 착용한 상태에서 벨트의 조건을 달리하였을 때 체 간 근육의 근활성도는 $\mathrm{A}$ 그룹, $\mathrm{B}$ 그룹, $\mathrm{C}$ 그룹 모두 경부척추 기립근과 상부승모근에서 유의한 차이를 보였으며 $(p<.05)$, 사후검정 $(\mathrm{LSD})$ 결과 경부척추기립근은 $\mathrm{A}$ 와 $\mathrm{B}$ 그룹에서 유 의한 차이를 보였고 $(p<.05)$, 상부승모근은 $\mathrm{A}$ 와 $\mathrm{C}$ 그룹에서 유의한 차이를 보였다 $(p<.05)$ (Table 2).

\subsection{Muscle activity in ascending walking}

가방을 착용한 상태에서 벨트의 조건을 달리하였을 때 체 간 근육의 근활성도는 $\mathrm{A}$ 그룹, $\mathrm{B}$ 그룹, $\mathrm{C}$ 그룹의 경부척추기립 근, 상부승모근 그리고 복직근 모두에서 유의한 차이를 보이 지 않았다(Table 3 ). 
Table 1. The general characteristics of the study subject

\begin{tabular}{|c|c|c|c|c|c|c|}
\hline \multicolumn{2}{|c|}{ Characteristics } & \multirow{2}{*}{$\begin{array}{c}\begin{array}{c}\text { Total } \\
(\mathrm{n}=75)\end{array} \\
13.24 \pm 0.08\end{array}$} & \multirow{2}{*}{$\begin{array}{c}\begin{array}{c}\text { A Group } \\
(\mathrm{n}=25)\end{array} \\
13.2 \pm 0.91\end{array}$} & \multirow{2}{*}{$\begin{array}{c}\begin{array}{c}\text { B Group } \\
(\mathrm{n}=25)\end{array} \\
13.24 \pm 0.72\end{array}$} & \multirow{2}{*}{$\begin{array}{c}\begin{array}{c}\text { C Group } \\
(\mathrm{n}=25)\end{array} \\
13.28 \pm 0.79\end{array}$} & \multirow{2}{*}{$\frac{p}{0.94}$} \\
\hline Age(yr) & & & & & & \\
\hline Height(cm) & & $153.89 \pm 7.44$ & $154.68 \pm 5.69$ & $152.24 \pm 7.65$ & $154.76 \pm 8.94$ & 0.78 \\
\hline Weight(kg) & & $48.3 \pm 8.72$ & $47.84 \pm 7.69$ & $47.76 \pm 10.49$ & $49.32 \pm 7.97$ & 0.40 \\
\hline \multirow{2}{*}{ Sex } & $\mathrm{M}$ & $43(57.3 \%)$ & $13(52 \%)$ & $16(64 \%)$ & $14(56 \%)$ & \multirow{2}{*}{0.69} \\
\hline & $F$ & $32(42.7 \%)$ & $12(48 \%)$ & $9(36 \%)$ & $11(44 \%)$ & \\
\hline \multirow{3}{*}{ Backpack weight } & Heavy & $29(38.7 \%)$ & $12(48 \%)$ & $8(32 \%)$ & $9(36 \%)$ & \multirow{3}{*}{0.96} \\
\hline & Fair & $30(40 \%)$ & $6(24 \%)$ & $13(52 \%)$ & $11(44 \%)$ & \\
\hline & Light & $16(22.3 \%)$ & $7(28 \%)$ & $4(16 \%)$ & $5(20 \%)$ & \\
\hline \multirow{2}{*}{ Use of belt } & Yes & $11(14.7 \%)$ & $3(12 \%)$ & $5(20 \%)$ & $3(12 \%)$ & \multirow{2}{*}{0.41} \\
\hline & No & $64(85.3 \%)$ & $22(88 \%)$ & $20(80 \%)$ & $22(88 \%)$ & \\
\hline \multirow{2}{*}{ Locker } & Use & $66(88 \%)$ & $23(92 \%)$ & $22(88 \%)$ & $21(84 \%)$ & \multirow{2}{*}{0.69} \\
\hline & Not use & $9(12 \%)$ & $2(8 \%)$ & $3(12 \%)$ & $4(16 \%)$ & \\
\hline \multirow{2}{*}{ Wearing mode } & One shoulder & $2(2.7 \%)$ & 0 & $2(8 \%)$ & 0 & \multirow{2}{*}{0.13} \\
\hline & Both Shoulder & $73(97.3 \%)$ & $25(100 \%)$ & $23(92 \%)$ & $25(100 \%)$ & \\
\hline \multirow{3}{*}{ Satisfaction } & Satisfactory & $34(45.3 \%)$ & $7(28 \%)$ & $15(60 \%)$ & $12(48 \%)$ & \multirow{3}{*}{0.20} \\
\hline & Fair & $28(37.3 \%)$ & $13(52 \%)$ & $5(20 \%)$ & $10(40 \%)$ & \\
\hline & Dissatisfactory & $13(17.3 \%)$ & $5(20 \%)$ & $5(20 \%)$ & $3(12 \%)$ & \\
\hline
\end{tabular}

A Group: no belt, B Group: lumbar belt, C Group: lumbar-chest belt

Table 2. EMG activites during carrying the backpacks in treadmill walking(Unit: \%MVC)

\begin{tabular}{c|c|c|c|c|c|c}
\hline & A Group & B Group & C Group & $F$ & $p$ & Post-hoc \\
\hline CES & $29.47 \pm 17.98$ & $19.92 \pm 11.32$ & $21.66 \pm 12.66$ & 3.147 & $0.048^{*}$ & A / B \\
\hline UT & $7.02 \pm 6.39$ & $4.88 \pm 4.47$ & $3.56 \pm 2.35$ & 3.847 & $0.026^{*}$ & A / C \\
\hline RA & $5.59 \pm 6.09$ & $3.91 \pm 2.35$ & $4.75 \pm 5.16$ & 0.762 & 0.471 & \\
\hline
\end{tabular}

${ }^{*} p<.05, \mathrm{~A}:$ no belt, B: lumbar belt, C: lumbar-chest belt

CES: cervical erector spinae, UT: upper trapezious, RA: rectus abdominis

Table 3. EMG activites during carrying the backpacks in ascending walking(Unit: \%MVC)

\begin{tabular}{c|c|c|c|c|c}
\hline & A Group & B Group & C Group & $F$ & $p$ \\
\hline CES & $51.09 \pm 31.94$ & $40.94 \pm 26.07$ & $38.7 \pm 20.69$ & 1.536 & 0.222 \\
\hline UT & $15.48 \pm 10.23$ & $9.85 \pm 5.47$ & $12.44 \pm 10.57$ & 2.385 & 0.099 \\
\hline RA & $10.12 \pm 15.04$ & $8.44 \pm 11.89$ & $5.62 \pm 3.64$ & 1.017 & 0.367 \\
\hline
\end{tabular}

A: no belt, B: lumbar belt, C: lumbar-chest belt

CES: cervical erector spinae, UT: upper trapezious, RA: rectus abdominis

\subsection{Muscle activity in descending walking}

가방을 착용한 상태에서 벨트의 조건을 달리하였을 때 체 간 근육의 근활성도는 $\mathrm{A}$ 그룹, $\mathrm{B}$ 그룹, $\mathrm{C}$ 그룹 모두 경부척추 기립근과 복직근에서 유의한 차이를 보였으며 $(p<.05)$, 사
후검정 $(\mathrm{LSD})$ 결과 경부척추기립근은 $\mathrm{A}$ 와 $\mathrm{B}$ 그룹, $\mathrm{A}$ 와 $\mathrm{C}$ 그 룹에서 유의한 차이를 보였고 $(p<.05)$, 복직근은 $\mathrm{A}$ 와 $\mathrm{B}$ 그룹, $\mathrm{A}$ 와 $\mathrm{C}$ 그룹에서 유의한 차이를 보였다( $p<.05)$ (Table 4). 
Table 4. EMG activites during carrying the backpacks in descending walking(Unit: \%MVC)

\begin{tabular}{c|c|c|c|c|c|c}
\hline & A Group & B Group & C Group & $F$ & $p$ & Post-hoc \\
\hline CES & $58.73 \pm 30.42$ & $41.89 \pm 23.44$ & $42.74 \pm 21.23$ & 3.503 & $0.035^{*}$ & A / BC \\
\hline UT & $14.03 \pm 9.88$ & $11.53 \pm 13.61$ & $8.66 \pm 6.12$ & 1.692 & 0.191 & \\
\hline RA & $11.10 \pm 10.77$ & $6.75 \pm 4.51$ & $5.73 \pm 3.03$ & 4.184 & $0.019^{*}$ & $\mathrm{~A} / \mathrm{BC}$ \\
\hline
\end{tabular}

${ }^{*} p<.05$, A: no belt, B: lumbar belt, C: lumbar-chest belt

CES: cervical erector spinae, UT: upper trapezious, RA: rectus abdominis

\section{Conclusion}

본 연구는 청소년이 가방을 착용한 상태에서 가방의 변수 를 달리하였을 때 체간 근육의 근활성도에 미치는 영향을 알 아보고자 근전도를 사용하여 실험을 실시하였다. 가방을 착 용하는 것은 체간의 자세와 근육의 활성화를 변화시킨다. 가 방 착용으로 인해 느끼는 불편함 중 가장 많이 보고되어 있 는 요인은 가방 무게이다(Ko \& Na, 2008). 이러한 가방 무 게는 많은 학생들이 허리, 어깨, 목 등에 정형외과적 통증을 유발하여 불편함을 호소하고 있다. 연구대상자들은 학교에서 의 배낭형 가방 사용 시 무겁다고 한 학생은 $38.7 \%$, 가볍다 고 한 학생은 $22.3 \%$, 적당하다 $40 \%$ 였다. 이것은 다수의 학생이 사물함 $88 \%)$ 을 이용하고 있기에 가방의 무게가 적 당하다고 답한 것으로 추정된다. 그리고 벨트를 사용하는 학 생은 $14.7 \%$, 사용하지 않는 학생은 $85.3 \%$ 였으며, 대부분의 학생들이 벨트를 사용하지 않고 있었다.

본 연구 결과를 보면 체간 근육의 근활성도는 가방의 벨트 를 착용하였을 때 보다 벨트를 착용하지 않았을 때 근활성도 가 높게 나타났으며, 트래드밀 보행보다는 계단 보행에서 경 부척추기립근, 상부승모근, 복직근의 근활성도가 높게 나타 나는 결과를 보였다. 경부척추기립근과 상부승모근은 부하 가 있을 때 체간의 중력중심선이 후방으로 이동되는 신전 모멘트를 만들고, 몸을 앞으로 기울이고 전방으로 이동함으 로써 균형을 잡아주게 된다(Bobet \& Norman, 1982). 그리 고 머리가 앞으로 이동되었을 때 무게의 이동에 대해 보상하 기 위하여 체간의 중력중심선이 앞쪽으로 이동될 것이고, 상 부 체간은 뒤쪽으로 이동하게 되는 것이다. 이러한 반복적인 움직임으로 인하여 경부척추기립근과 상부승모근의 근활성 도가 높게 나타난다(Kim et al., 2008).

하지만 허리 및 허리-흥부 벨트를 착용한 후 체간 근육의 근활성도는 감소되었다. 이것은 가방의 벨트를 착용함으로써 체간에서의 안정성을 증가시키고, 가방의 움직임을 최소화 함으로써 근활성도가 감소된 것으로 생각된다.

복직근은 외부의 부하가 없을 때 체간 안정화에 사용되는 근육은 아니지만 배낭을 착용하는 것과 같이 체간의 신전 모
멘트가 발생하는 상황에서는 이를 상쇄시키기 위해 체간을 굴곡시키는 근육이다(Pascoe et al., 1997; Filiaire et al., 2001). 가방의 무게 중심이 뒤쪽에 부하가 되면 복직근이 체간을 바로 세우기 위하여 허리를 뒤로 가져가기 위한 중요 한 역할을 할 것이며, 복직근은 척추안정성에 기여하며 이런 근육의 지연된 작용은 체간 근육 조절에 취약하여 결국엔 요 통을 일으키게 된다(Hodges \& Richardson, 1996).

Hong와 brueggeman (2000)에 의하면 복직근은 높은 부 하를 운반할 때 체간의 전, 후 흔들림 (swing) 의 증가는 복 부, 등 그리고 다리의 근육이 동적 균형을 유지하기 위해서 근활성도가 증가된다고 하였다. 하지만 본 연구 결과 가방의 벨트를 착용함으로써 복직근의 움직임을 최소화 하기 위해 그리고 체간을 대칭적으로 균형을 잡게 함으로써 근활성도 가 감소되었다고 할 수 있다.

계단 보행은 계단을 오를 때 계단의 경사면과 체간이 앞으 로 평형하게 기우는 경향이 있다는 것을 보고하였다(kerbs et al., 1992). 그리고 계단에서의 보행은 불안정성의 위험이 있거나 일반적인 보행에서보다 더 많은 안정성이 필요하며, 가방의 무게부하로 인하여 이동 시스템의 중력 중심이 높아 지고 평형 안정성을 감소시켜 균형을 유지하기 위해 더 많은 근활동이 필요하다고 하였다(Loy \& Volosin, 1991).

Riener 등 (2002)은 계단 보행에서의 체간 근육은 외적 부하 효과 때문에 변화로부터 체간을 안정시키기 위해 근활 성도가 증가하였다고 하였으며, 정상적으로 계단을 오를 때 부하는 같은 수준으로 걸을 때 보다 $180 \%$ 를 넘는다고 하였 다. Hong과 $\operatorname{Li}(2005)$ 는 계단을 걸어서 내려가는 것의 물리 적 행동이 걸어서 계단을 올라가는 것보다 아이들의 근골격 계에 더 높은 동적부하의 결과를 미친다고 하였다. 이것은 본 연구에서도 계단오르기 보행보다는 계단내리기 보행에서 체간 근육의 근활성도가 높다는 연구 결과와 같은 결과를 보 였다. LSD 사후분석 결과 벨트를 착용하였을 때가 벨트를 착용하지 않았을 때보다 경부척추기립근, 상부승모근, 복직 근의 근활성도가 감소되었다. 이것은 가방의 벨트를 사용하 였을 때 체간 근육의 근활성도가 감소된다는 증거를 나타내 는 것이다.

본 연구 결과 배낭형 가방 착용이 어깨의 힘과 압력에 큰 
영향을 미쳤고, 엉덩이벨트의 사용과 느슨한 어깨 스트랩의 사용은 어깨의 힘을 감소 시켰으며, 엉덩이 및 허리 그리고 복부 부분에 의해 발생되는 무게에 벨트를 사용함으로써 어 깨에 발생되는 압력을 감소시킨다고 한 Mackie 등(2005) 의 연구와 일치하였다. 배낭형 가방 착용 시 벨트를 착용하 지 않는 학생보다 벨트를 착용한 학생이 통계적으로 유의한 차이를 보인다는 것은 벨트를 착용하였을 때 체간 근육의 근활성도가 감소된다는 것을 알 수 있다. 따라서 배낭형 가 방을 착용함에 있어 허리, 흉부 벨트의 착용이 학생들에게서 발생되는 나쁜 자세, 요통 그리고 근골격계 문제를 감소시킬 것으로 예상이 된다. 그리고 벨트를 착용하지 않는 학생들이 많은 것 $(85.3 \%)$ 은 학교에서의 가방을 착용함에 있어 현장 교육도 필요할 것이라 제안하고 싶다.

그러나 본 연구는 제한된 표본의 수, 실제 보행이 아닌 트 래드밀에서의 보행이라는 제한점과 가방을 메는 행위가 운 동자각도 9 13등급에 해당하는 청소년들에 있어 지극히 일 상적인 행위이기 때문에 실험 전후에 주관적인 평가를 하지 않았다. 향후 연구에서는 하지의 근활성도 및 전방머리 자세 등의 연구가 필요할 것으로 사료된다.

\section{References}

Bobet, J. and Norman, R. W., Use of the average electromyogram in design evaluation. Investigation of a whole-body task, Ergonomics, 25(12), 1155-1163, 1982.

Chansirinukor, W., Wilson, D., Grimmer, K. and Dansie, B., Effects of backpacks on students: measurement of cervical and shoulder posture, Aust J Physiother, 47(2), 110-116, 2001.

Cram, J. R, Kasman, G. S. and Holtz, J., Introduction to Surface Electomyography. Gaitherburg, Aspen Pub, 1998.

Filiaire, M., vacheron, J. J., Vanneuville, G., Poumarat, G., Garcier, J. M., Harouna, Y., Guillot, M., Terver, S., Toumi, H. and Therry, C., Influence of the mode of load carriage on the static posture of the pelvic girdle and the thoracic and lumbar spine in vivo, Surg Radiol Anat, 23(1), 27-31, 2001.

Forjuoh, S. N., Lane, B. L. and Schuchmann, J. A., Percentage of body weight carried by students in their school backpacks, Am J Phys Med Rehabil, 82(4), 261-266, 2003

Gong, W. T., Han, J. T. and Ro, H. L., The influence of contract-?relax exercise on functional leg length inequality and muscle activity, $J$ Kor Soc Phys Ther, 21(1), 49-56, 2009.

Grimmer, K. A., Williams, M. T. and Gill, T. K., The associations between adolescent head-on-neck posture, backpack weight and anthropometric features, Spine, 1(24), 2262-2267, 1999.

Hodges, P. W. and Richardson, C. A., Inefficient muscular stabilization of the lumbar spine associated with low back pain. A motor control evaluation of transversus abdominis, Spine, 15(22), 2640-2650, 1996.

Hong, Y. and Li, J. X., Influence of load and carrying methods on gait phase and ground reactions in children's stair walking, Gait Posture, 22(1), 63-68, 2005.

Hong, Y., Li, J. X., Wong, A. S. and Robinson, P. D., Effects of load carriage on heartrate, blood pressure and energy expenditure in children, Ergonomics, 43(6), 717-727, 2000.

Hong Kong Society for Child Health and Development. The weight of school bags and its relation to spinal deformity. Hong kong: The Department of Orthopaedic surgey, University of Hong Kong, The Duchess of kent Children's Hospital, 1988.

Hong, Y. and Brueggemann, G. P., Changes in gait patterns in 10-year-old boys with increasing loads when walking on a treadmill, Gait Posture, 11(3), 254-259, 2000

Jo, S. C., Effects of backpack weight on elementary school boy's walking, Korean Soc Sports Med, 19(2), 303-310, 2001.

Kerbs, D. E., Wong. D. and Jevsevar. D., Trunk Kinematics During Locomotor Activities. Phys Ther, 72(7), 505-514, 1992.

Kim, M. H., Yi, C. H., Kwon, O. Y., Cho, S. H. and Yoo, W. G., Changes in neck muscle electromyography and forward head posture of children when carrying schoolbags, Ergonomics Jun, 51(6), 890-901, 2008.

Ko, K. H. and NA, Y. J., Investigation on the purchasing criteria and discomfort of school backpack for adolescents, Journal Korean society of clothing and textiles, 32(8), 1179-1189, 2008.

Lee, S. Y., Son, G. S., Jeon, H. J. and Lee, M. H., The effects of therapeutic exercise on the balance and gait in older adults, J Kor Soc Phys Ther, 19(2), 1-10, 2007.

Limon, S., Valinsky, L. J. and Ben-Shalom, Y., Children at risk: Risk factors for low back pain in the elementary school environment, Spine, 29(6), 697-702, 2004.

Loy, D. J. and Voloshin, A. S., Biomechaics of stair walking and jumping, J Sports Sci, 9(2), 137-149, 1991.

Mackie, H. W., Stevenson, J. M., Reid, S. A. and Legg, S. J., The effect of simulated school load carriage configurations on shoulder strap tension forces and shoulder interface pressure, Applied Ergonomics, 36, 199-206, 2005.

Motmans, R. R, Tomlow, S. and Vissers, D., Trunk muscle activity in different modes of carrying schoolbags, Ergonomics, 49(2), 127-138, 2006.

Negrini, S. and Carabalona, R., Backpacks on! Schoolchildren's perceptions of load associations with back pain and factors determining the load, Spine, 27(2), 187-195, 2002.

Oh, J. H. and Choi, S. N., Effects of the length of schoolbag on gait posture Journal of sport and leisure studies, 30, 619-629, 2007.

Pascoe, D. D., Pascoe, D. E., Wang, Y. T., Shim, D. M. and Kim, C. K., Influence of carrying book bags On gait cycle and posture of youths, Ergonomics, 40(6), 631-641, 1997.

Riener, R., Rebuffetti, M. and Frigo, C., Stair ascent and descent at different inclinations, Gait Posture, 15(1), 32-44, 2002

Whittfield, J. K., legg, S. J. and Hwdderly, D. I., The weignt and use of schoolbags in NewZealand secondary schools, Ergonomics, 44(9), 819-824, 2001 
Wong, A. S. K. and Hong, Y., Walking pattern analysis of primary school children during load carriages on treadmill, Med Sci Sports Exerc, 29(5), 85, 1997.

\section{Author listings}

Yong Soo Kong: twinkong@hanmail.net

Highest degree: Department of Phygical Therapy, General Graduate

School, Catholic University of Daegu

Position title: Phygical therapist, Fatima clinic

Areas of interest: Prevention and Treatment for Musculoskeletal disorder,

Posture, Motion analysis and EMG
Jang Soon Yoon: ptyjs@hanmail.net

Highest degree: $\mathrm{PhD}$, Department of physical therapy, Hallym University Position title: Physical therapist, Hallym University

Areas of interest: Rehabilitation and physical therapy for Musculoskeletal disorder, and Neurological disorder

Date Received : 2012-10-10

Date Revised : 2012-11-30

Date Accepted : 2012-12-03 